\title{
RESEARCH
}

\section{DIETARY TOTAL ANTIOXIDANT CAPACITY AND DIVERSITY: A COMPARISON STUDY OF OLDER AND YOUNGER ADULTS}

Turkish Journal of Geriatrics

DOI: $10.31086 /$ tigeri.2021.210

2021; 24(2): 150-158

- Ece YALÇIN ${ }^{1}$

- Izzet YAVUZ ${ }^{2}$

- Neslişah RAKICIOĞLU3

CORRESPONDANCE

${ }^{3}$ Neslişah RAKICIOĞLU

Hacettepe University Faculty of Health

Sciences, Nutrition and Dietetics, Ankara, Turkey

\section{Phone: +903123119649 \\ e-mail: neslisah@hacettepe.edu.tr}

Received: Feb 17, 2020

Accepted: May 24, 2021

${ }^{1}$ Hacettepe University Faculty of Health Sciences, Nutrition and Dietetics, Ankara, Turkey

${ }^{2}$ Lokman Hekim Ankara Hospital, Internal Medicine, Ankara, Turkey

\section{${ }^{3}$ Hacettepe University Faculty of Health} Sciences, Nutrition and Dietetics, Ankara, Turkey

\section{Abstract}

Introduction: The present study aimed to assess the dietary total antioxidant capacity and diversity among older and younger adults.

Materials and Methods: In total, 38 older adults aged $\geq 65$ years and 38 younger adults aged between 19 and 30 years were included in the study. The participants' general characteristics, dietary habits, and three-day dietary intake records were assessed. The dietary total antioxidant capacity and diversity score were calculated from the dietary intake records. Moreover, the serum total antioxidant capacity and oxidant status were assessed using commercial kits.

Results: The dietary diversity was greater among the younger adults than among the older adults $(p<0.05)$. According to the dietary total antioxidant capacity values calculated from various databases, in males, the lipophilic and total oxygen radical absorbance capacity values were significantly lower among the older adults than among the younger adults. In females, the hydrophilic and total oxygen radical absorbance capacity, total phenol, and ferric reducing antioxidant power values were significantly lower among the older adults than among the younger adults. The serum total oxidant status and oxidative stress index of the older adults were significantly higher than those of the younger adults $(p<0.05)$. Furthermore, the dietary diversity score and serum total antioxidant capacity were associated with the dietary total antioxidant capacity.

Conclusion: With aging, the dietary total antioxidant capacity and diversity decrease, while the oxidative stress index increases. Therefore, the consumption of foods with high antioxidant capacity and dietary diversity should be encouraged among older adults.

Keywords: Antioxidants; Oxidative Stress; Dietary Intake; Aging 


\section{INTRODUCTION}

As in the rest of the world, the older adult population has substantially increased in Turkey (1). With an increase in life expectancy, the incidence of age-related diseases has also increased (2). Aging is a complex and inevitable process; many theories have been proposed to explain this process. Recently, the oxidative stress (or free radical) theory has become the most important theory explaining aging at the molecular level. According to this theory, the imbalance between antioxidants and oxidants with an increase in age leads to the accumulation of oxidative damage in many macromolecules, thereby diminishing the functions of various systems in the body and giving rise to the phenotype of aging (3). Antioxidants protect cells and organs against oxidative stress. Therefore, the intake of nutrients and dietary components that are rich in antioxidants is crucial for protecting the body against oxidative stress. The dietary intake of antioxidants is greatly influenced by an individual's dietary habits and preferences (4). The dietary total antioxidant capacity (TAC) is a parameter that evaluates antioxidants as a whole and takes into account the synergistic effects among antioxidants. The combination of different antioxidants provides more protection against reactive species than a single antioxidant. The dietary TAC is a valuable screening tool in nutritional epidemiology studies and plays an important role in the development of a better nutrition program for individuals (5). Exogenous and endogenous antioxidants together neutralize reactive species and prevent oxidative stress. Therefore, several ways have been suggested to increase the amount of exogenous antioxidants $(4,5)$. The present study aimed to assess the daily consumption of some food groups by older and younger adults and to evaluate their dietary and serum TAC status.

\section{MATERIALS AND METHODS}

The present study had a cross-sectional design to evaluate the dietary and serum TAC status of older and younger adults. In total, 38 older adult volunteers ( 13 males and 25 females) aged $\geq 65$ years and 38 younger adult volunteers ( 13 males and 25 females) aged between 19 and 30 years participated in the study, which was conducted at a private hospital in Ankara between May 2017 and May 2018. The study was conducted with the approval of the Hacettepe University Ethics Commission (dated 03/14/2017 and numbered GO 17/212-30). None of the participants had a history of metabolic or endocrine diseases, except for hypertension. Moreover, none of them had smoked or consumed alcohol and used food supplements in the past year.

\section{Dietary energy and nutrient intakes, antioxidant capacity, and diversity score}

Dietary intakes were recorded for three consecutive days (including a weekend day). Energy and nutrient intakes were calculated using BeBIS 8.1 (Nutrition Information System software 2017). Dietary TAC values were calculated using databases of oxygen radical absorbance capacity (ORAC) and ferric reducing antioxidant power (FRAP) $(6,7)$. The dietary diversity score (DDS) was calculated by considering five main food groups: cereal, vegetable, fruit, meat, and milk. The serving size was determined to take into consideration the dietary guidelines for Turkey (8). If the mean daily consumption of a food group by an individual was more than half the recommended portion, the individual was considered to have consumed that food group. DDSs were classified as low (DDS $<3$ ), medium $(3<$ DDS $<6$ ), and high (DDS > 6) (9).

\section{Serum TAC and oxidant status}

The serum TAC and total oxidant status (TOS) were assessed using commercial kits (Rel Assay Diagnostics) (10, 11). The samples were studied in duplicates. The serum TAC was measured according to the bleaching of the characteristic color of a more stable 2.20-azinobis (3-ethylbenzothiazo- 
line-6-sulfonic acid) (ABTS) radical cation by antioxidants (10). Furthermore, the serum TOS was measured according to the total amount of oxidant molecules present in the sample. The analysis was calibrated with hydrogen peroxide; the results are expressed in terms of micromolar hydrogen peroxide equivalent per liter (mmol $\mathrm{H}_{2} \mathrm{O}_{2} \mathrm{Eq} / \mathrm{L}$ ). The serum TOS was measured according to the oxidation

Table 1. General characteristics of the study participants

\begin{tabular}{|c|c|c|c|c|c|c|c|c|c|c|c|c|c|}
\hline & \multicolumn{6}{|c|}{ Older adults } & \multicolumn{6}{|c|}{ Younger adults } & \multirow{3}{*}{$p$} \\
\hline & \multicolumn{2}{|c|}{$\begin{array}{c}\text { Male } \\
(n=13)\end{array}$} & \multicolumn{2}{|c|}{$\begin{array}{l}\text { Female } \\
(\mathrm{n}=25)\end{array}$} & \multicolumn{2}{|c|}{ Total } & \multicolumn{2}{|c|}{$\begin{array}{c}\text { Male } \\
(n=13)\end{array}$} & \multicolumn{2}{|c|}{$\begin{array}{l}\text { Female } \\
(\mathrm{n}=25)\end{array}$} & \multicolumn{2}{|c|}{ Total } & \\
\hline & $\mathrm{n}$ & $\%$ & $\mathrm{n}$ & $\%$ & $\mathrm{n}$ & $\%$ & $\mathrm{n}$ & $\%$ & $\mathrm{n}$ & $\%$ & $n$ & $\%$ & \\
\hline Age (years) $)^{\dagger}$ & \multicolumn{2}{|c|}{$72.1 \pm 6.71$} & \multicolumn{2}{|c|}{$71.3 \pm 6.71$} & \multicolumn{2}{|c|}{$71.6 \pm 6.63$} & \multicolumn{2}{|c|}{$23.5 \pm 3.69$} & \multicolumn{2}{|c|}{$24.5 \pm 3.37$} & \multicolumn{2}{|c|}{$24.2 \pm 3.47$} & $<0.001^{*}$ \\
\hline \begin{tabular}{|c|}
$\begin{array}{c}\text { Total duration of educa- } \\
\text { tion }^{\dagger} \text { (years) }\end{array}$ \\
\end{tabular} & \multicolumn{2}{|c|}{$5.9 \pm 5.6$} & \multicolumn{2}{|c|}{$3.3 \pm 2.6$} & \multicolumn{2}{|c|}{$4.2 \pm 3.3$} & \multicolumn{2}{|c|}{$14.1 \pm 3.3$} & \multicolumn{2}{|c|}{$14.2 \pm 2.4$} & \multicolumn{2}{|c|}{$14.2 \pm 2.7$} & $<0.001^{*}$ \\
\hline \multicolumn{14}{|l|}{ Marital status (\%) } \\
\hline Married & 12 & 92.3 & 19 & 76.0 & 31 & 81.6 & 4 & 30.8 & 10 & 40.0 & 14 & 36.8 & \multirow{2}{*}{$<0.001^{a *}$} \\
\hline Bachelor & 1 & 7.7 & 6 & 24.0 & 7 & 19.4 & 9 & 69.2 & 15 & 60.0 & 24 & 63.2 & \\
\hline \multicolumn{14}{|l|}{ Smoking status (\%) } \\
\hline Never & 4 & 30.8 & 24 & 96.0 & 28 & 75.7 & 13 & 100.0 & 24 & 96.0 & 37 & 97.4 & \multirow[b]{2}{*}{$0.003^{a *}$} \\
\hline $\begin{array}{l}\text { Yes (except for the past } \\
\text { year) }\end{array}$ & 9 & 69.2 & 1 & 4.0 & 10 & 23.3 & - & - & 1 & 4.0 & 1 & 2.6 & \\
\hline \multicolumn{13}{|l|}{ Alcohol use (\%) } & \\
\hline Never & 11 & 83.3 & 25 & 100.0 & 36 & 94.7 & 12 & 92.3 & 23 & 92.0 & 35 & 92.1 & \multirow[b]{2}{*}{$0.615^{a}$} \\
\hline $\begin{array}{l}\text { Yes (except for the past } \\
\text { year) }\end{array}$ & 2 & 16.7 & - & - & 2 & 5.3 & 1 & 7.7 & 2 & 8.0 & 3 & 7.9 & \\
\hline \multicolumn{14}{|l|}{ Disease diagnosis (\%) } \\
\hline No & 10 & 76.9 & 6 & 24.0 & 16 & 42.1 & 13 & 100.0 & 18 & 72.0 & 31 & 81.6 & \multirow[t]{2}{*}{$0.002^{a \star}$} \\
\hline Yes & 3 & 23.1 & 19 & 76.0 & 22 & 57.9 & - & - & 7 & 28.0 & 7 & 18.4 & \\
\hline Type of disease (\%) & & & & & & & & & & & & & \\
\hline Hypertension & 3 & 100.0 & 14 & 82.3 & 17 & 85.0 & - & - & - & - & - & - & \\
\hline Ulcer-gastritis & - & - & 2 & 11.8 & 2 & 10.0 & - & - & 2 & 100.0 & 2 & 100.0 & \\
\hline Osteoporosis & - & - & 1 & 5.9 & 1 & 5.0 & - & - & - & - & - & - & \\
\hline $\begin{array}{l}\text { Dietary habits } \\
\text { Mean meal number }{ }^{\dagger}\end{array}$ & & & & & & & & & & & & & \\
\hline Main meals & & \pm 0.51 & & \pm 0.44 & & 0.48 & & \pm 0.44 & & $=0.46$ & & \pm 0.45 & 0.460 \\
\hline Snacks & & \pm 0.49 & & \pm 0.57 & & 0.54 & & \pm 0.78 & & $=0.76$ & 1.5 & \pm 0.76 & $0.001^{*}$ \\
\hline Skipping meals (\%) & & & & & & & & & & & & & \\
\hline No & 1 & 7.7 & 3 & 12.0 & 4 & 10.6 & 3 & 23.1 & 4 & 16.0 & 7 & 18.4 & \\
\hline Yes & 12 & 92.3 & 22 & 88.0 & 34 & 89.4 & 10 & 76.9 & 21 & 84.0 & 31 & 81.6 & \\
\hline
\end{tabular}

Mann-Whitney $U$ test; $p$ value: tested between the older and younger adults

a Pearson's chi-squared test, ${ }^{*} \mathrm{p}<0.05$

$\dagger(\xi \pm \mathrm{SD}$ 
of the ferrous ion to the ferric ion in the presence of various oxidative species in the acidic medium; the results are expressed in terms of $\mathrm{mmol} \mathrm{H}_{2} \mathrm{O}_{2} \mathrm{Eq} / \mathrm{L}$ (11). The oxidative stress index (OSI) was calculated as a percentage by dividing the total oxidant state by the TAC.

\section{Statistical analysis}

Statistical analyses were performed using SPSS 23 (Statistical Software Package 23, IBM Corp., Armonk, NY, USA). The results are presented as the mean \pm standard deviation $(\xi \pm \mathrm{SD})$ values. Qualitative data are expressed as numbers and percentages. Normally distributed data were analyzed using parametric statistical tests (independent two-sample t test and Pearson's correlation), whereas non-normally distributed data were analyzed using nonparametric statistical tests (Pearson's chi-squared test, Mann-Whitney $U$ test, and Spearman's correlation). $p<0.05$ was considered the cutoff value for significance.

\section{RESULTS}

In total, 38 older adults and 38 younger adults participated in the present study; their mean ages were $71.6 \pm 6.63$ and $24.2 \pm 3.47$ years, respectively. General characteristics of the study participants are provided in Table 2. The mean duration of education was significantly lower among the older adults $(4.2 \pm$ 4.0 years) than among the younger adults $(14.2 \pm 2.7$ years) ( $p<0.001)$. In total, $75.7 \%$ of the older adults and $97.4 \%$ of the younger adults were non-smokers ( $p<0.05$ ). Moreover, $57.9 \%$ of the older adults and $18.4 \%$ of the younger adults were diagnosed with a disease $(p<0.05)$. Hypertension was the most common disease among the older adults (77.3\%), while ulcer-gastritis was the most common disease among the younger adults (28.6\%). Although their mean main meal numbers were similar, the mean number of snacks consumed by the older adults (1.1 \pm 0.54 ) was significantly lower than that consumed by the younger adults $(1.6 \pm 0.76)(p<0.05)$. However, there was no significant difference between these two groups in terms of skipping meals $(p>$ 0.05).

The mean daily food consumption and DDSs of the older and younger adults are provided in Table 2. In males, the daily consumption of meats was found to be significantly lower among the older adults than among the younger adults $(p<0.05)$. In females, bread consumption was found to be significantly lower among the older adults than the younger adults $(p<0.05)$.

According to the DDS classification, 53.2\% of the older adults were considered to have a medium DDS, while $36.8 \%$ were considered to have a low DDS. These values were $73.7 \%$ and $18.4 \%$, respectively, for the younger adults $(p<0.05)$.

The dietary TAC, serum antioxidant capacity, and serum oxidant status of the older and younger adults are provided in Table 3. According to the mean dietary TAC values, in males, the lipophilic ORAC (L-ORAC) and total ORAC (T-ORAC) values were significantly lower among the older adults than the younger adults. Furthermore, in females, the hydrophilic ORAC (H-ORAC), T-ORAC, total phenol (TP), and FRAP values were significantly lower among the older adults than among the younger adults. The serum TOS and OSI were significantly higher among the older adults than among the younger adults $(p<0.05)$. However, there was no significant difference in the serum TAC between the two groups ( $p>0.05)$.

The correlations between DDSs and different dietary TAC measures are provided in Table 4. In the study, there was a mid-level correlation between the DDS and L-ORAC $(r=0.398, p<0.001)$. Moreover, there was a mid-level correlation between the DDS and H-ORAC, T-ORAC, and TP values $(p<0.05)$. However, there was a weak correlation between the serum TAC and H-ORAC $(r=0.204)$ and T-ORAC ( $r$ $=0.203)(p<0.05)$. 
Table 2. Mean daily consumption of food groups and dietary diversity scores among older and younger adults

\begin{tabular}{|c|c|c|c|c|c|c|}
\hline & \multicolumn{2}{|c|}{ Older adults $(n=38)$} & \multicolumn{3}{|c|}{ Younger adults $(n=38)$} & \multirow[b]{2}{*}{$p_{2}$} \\
\hline & $\begin{array}{c}\text { Male } \\
(n=13)\end{array}$ & $\begin{array}{l}\text { Female } \\
(\mathrm{n}=25)\end{array}$ & $\begin{array}{c}\text { Male } \\
(n=13)\end{array}$ & $\begin{array}{l}\text { Female } \\
(n=25)\end{array}$ & $p_{1}$ & \\
\hline \multicolumn{7}{|l|}{ Food groups (g day ${ }^{-1}$ ) } \\
\hline Milk and milk products & $175.5 \pm 70.1$ & $157.9 \pm 71.2$ & $163.1 \pm 56.6$ & $188.5 \pm 115.3$ & $0.555^{\mathrm{a}}$ & $0.491^{\mathrm{a}}$ \\
\hline Bread and cereals & $145.0 \pm 79.7$ & $142.8 \pm 52.4$ & $156.9 \pm 118.9$ & $102.8 \pm 77.7$ & $1.000^{\mathrm{a}}$ & $0.006^{a *}$ \\
\hline Vegetables and fruits & $169.6 \pm 89.9$ & $154.8 \pm 77.8$ & $237.7 \pm 130.1$ & $193.7 \pm 83.4$ & $0.191^{a}$ & $0.093^{a}$ \\
\hline Meats & $114.6 \pm 44.8$ & $117.7 \pm 68.1$ & $195.9 \pm 144.6$ & $146.4 \pm 84.4$ & $0.022^{*}$ & 0.162 \\
\hline Eggs & $24.9 \pm 23.4$ & $29.8 \pm 19.9$ & $37.3 \pm 33.6$ & $33.5 \pm 32.6$ & 0.429 & 0.824 \\
\hline Pulses and nuts & $7.9 \pm 17.2$ & $8.5 \pm 11.9$ & $8.1 \pm 15.7$ & $11.6 \pm 16.0$ & 0.740 & 0.313 \\
\hline Fats and oils & $43.3 \pm 14.1$ & $39.4 \pm 21.3$ & $44.1 \pm 29.5$ & $37.3 \pm 17.3$ & 0.573 & 0.961 \\
\hline Sweets & $33.7 \pm 94.1$ & $10.7 \pm 11.8$ & $12.9 \pm 16.1$ & $19.2 \pm 37.9$ & 0.979 & 0.838 \\
\hline DDS† & \multicolumn{2}{|c|}{ n (\%) } & \multicolumn{2}{|c|}{ n (\%) } & \multicolumn{2}{|c|}{$\mathrm{p}$} \\
\hline$<3$ & \multicolumn{2}{|c|}{$14(36.8)$} & \multicolumn{2}{|c|}{$7(18.4)$} & \multirow{3}{*}{\multicolumn{2}{|c|}{$0.033^{\star \star}$}} \\
\hline $3-6$ & \multicolumn{2}{|c|}{$24(53.2)$} & \multicolumn{2}{|c|}{$28(73.7)$} & & \\
\hline$>6$ & \multicolumn{2}{|c|}{-} & \multicolumn{2}{|c|}{$3(7.9)$} & & \\
\hline
\end{tabular}

Mann-Whitney $U$ test; $p_{1}$ value: tested between male older and younger adults; $p_{2}$ value: tested between female older and younger adults

aStudent's t test, ${ }^{*} \mathrm{p}<0.05$

${ }^{\dagger} n(\%),{ }^{*}$ Pearson's chi-squared test

DDS: dietary diversity scor

\section{DISCUSSION}

Oxidative stress affects the nervous system, endocrine system, and immune system; it damages cells and consequently causes many diseases (12). Studies have shown that the prevalence of diseases caused by oxidative stress can be reduced by dietary interventions $(13,14)$. Due to their antioxidant properties, nutrients protect the body against oxidative stress throughout life (5). Because oxidative stress increases during the aging process, the consumption of antioxidant-rich and diverse foods becomes increasingly important with age. The present study aimed to evaluate the dietary TAC and diversity status among older and younger adults. In total, $75.7 \%$ of the older adults and $97.4 \%$ of the younger adults were non-smokers. The percentage of older and younger adults who never consumed alcohol was similar (92.1\% and $94.7 \%$, respectively). Many studies have shown that smoking and alcohol consumption affect the TAC and oxidative stress markers $(15,16)$. Therefore, it is important to note that none of the participants had a history of smoking or alcohol consumption in the previous past year. Hypertension commonly occurs in older adults because of vascular damage caused by aging (17). In the present study, $44.7 \%$ of the older adults were diagnosed with hypertension. The older adult participants had no chronic or metabolic disease other than hypertension and osteoporosis; this is a relevant observation because diseases and related diets, medications and supplementation may affect nutrition. 
In the present study, the participants' daily food consumption was assessed. In females, although meat consumption differed between the younger and older adults, the difference was not significant. However, in males, the daily consumption of meats was significantly lower among the younger adults than the older adults (Table 2$)(p<0.05)$. High consumption of foods such as milk and milk products, meat, and eggs, which are good sources of proteins for older adults, preserves muscle strength (18). In the present study, in females, the consumption of bread and cereals was significantly higher among the older adults than the younger adults (Table 2) $(p<0.05)$. Bread, rice, and bulgur are the most important sources of energy for Turkish people (19). In addition, owing to their simple preparation and easy digestion, the consumption of these foods may have increased among older females. The mean consumption of vegetables and fruits was less than $400 \mathrm{~g}$ per day in both the age groups (Table 2). The WHO recommends that the daily consumption of fresh vegetables and fruits should be above $400 \mathrm{~g}$ for healthy nutrition (20). The consumption of other foods was similar between the older and younger adults. Regular nutrition and not skipping main meals had a positive effect on dietary intake among the older adults. Thus, in the present study, food consumption was similar between the older and younger adults. Although the daily consumption of most food groups was similar between the two age groups, the dietary diversity was lower among the older adults than among the younger adults (Table 2) $(p<0.05)$. The DDS is an important indicator of a quality diet; a low DDS is associated with significant health problems in both older and younger adults (21). In a 12-year longitudinal study involving 40-79-year-old individuals, Otsuka et al. (22) reported a decrease in DDSs in individuals older than 50-60 years. Many factors, such as physical and physiological changes and socioeconomic circumstances, can affect the nutritional status of older adults. Thus, the dietary diversity decreases in older adults (18).
In males, the L-ORAC and T-ORAC values were significantly lower among the older adults than the younger adults. Moreover, in females, the H-ORAC, T-ORAC, TP, and FRAP values were significantly lower among the older adults than the younger adults (Table 3) ( $<<0.05)$. Zujko et al. (23) have reported similar results to those of the present study, with the dietary TAC calculated with FRAP being lower in males and females aged 61-74 years than in younger adults. The dietary TAC may decrease with a change in dietary preferences and a decrease in the dietary diversity due to changes that occur during the aging process (18). In the present study, a significant correlation was noted between the dietary TAC and DDS (Table 4) ( $p<0.05)$.

The serum TAC and oxidant status, which are two important indicators of oxidative stress, change during the aging process, thereby increasing oxidative stress $(10,11)$. In the present study, the serum TAC of the older adults $(1.586 \pm 0.26 \mathrm{mmol} / \mathrm{L})$ was lower than that of the younger adults $(1.684 \pm 0.26$ $\mathrm{mmol} / \mathrm{L})$; however, the difference was not significant $(p=0.103)$ (Table 3 ). The serum oxidant status and OSI were significantly higher among the older adults than among the younger adults $(p<0.001)$, probably due to the increase in reactive oxygen species during the aging process. Narmaki et al. (24) reported that enhancing the dietary diversity can reduce oxidative stress. A weak positive but significant relationship was noted between the dietary TAC and serum TAC ( $p<0.05)$ (Table 4). Similarly, Wang et al. (25) demonstrated a significant relationship between the dietary TAC and serum TAC in adults. The contribution of nutrients to the TAC depends on food ingredients (4). In the present study, the percentage of individuals consuming a wide variety of ingredients was low (3.9\%) according to the nutrition diversity score.

\section{CONCLUSION}

In the present study, the mean dietary TAC was higher among the younger adults, whereas the serum 
Table 3. Dietary and serum total antioxidant capacity and serum oxidant status of older and younger adults

\begin{tabular}{|c|c|c|c|c|c|c|c|}
\hline & \multicolumn{3}{|c|}{ Older adults $(n=38)$} & \multicolumn{2}{|c|}{ Younger adults $(n=38)$} & & \\
\hline & $\begin{array}{c}\text { Male } \\
(n=13)\end{array}$ & $\begin{array}{l}\text { Female } \\
(n=25)\end{array}$ & $\begin{array}{c}\text { Male } \\
(n=13)\end{array}$ & $\begin{array}{l}\text { Female } \\
(n=25)\end{array}$ & & & \\
\hline & $\bar{x} \pm S D$ & $\bar{x} \pm S D$ & $\bar{x} \pm S D$ & $\bar{x} \pm S D$ & $p_{1}$ & $p_{2}$ & \\
\hline \multicolumn{8}{|l|}{ Dietary TAC } \\
\hline $\begin{array}{l}\text { Hydrophilic ORAC } \\
\text { ( } \mu \mathrm{mol} \text { TE) }\end{array}$ & $14111 \pm 3493.6$ & \multicolumn{2}{|c|}{$11760 \pm 2492.9$} & $16312 \pm 4300.9$ & $14895 \pm 5031.2$ & $0.086^{a}$ & 0.017 * \\
\hline $\begin{array}{l}\text { Lipophilic ORAC } \\
\text { ( } \mu \mathrm{mol} \text { TE) }\end{array}$ & $1087.2 \pm 602.2$ & \multicolumn{2}{|c|}{$1121.7 \pm 465.2$} & $2089.1 \pm 1667.1$ & $1229.1 \pm 835.5$ & $0.044^{\star}$ & 0.961 \\
\hline $\begin{array}{l}\text { Total ORAC } \\
(\mu \mathrm{mol} \text { TE })\end{array}$ & $15210 \pm 3921.8$ & \multicolumn{2}{|c|}{$12897 \pm 2509.4$} & $18543 \pm 5608.6$ & $16159 \pm 5407.3$ & $0.046^{a *}$ & $0.028 *$ \\
\hline TP (GAE) & $895.6 \pm 279.8$ & \multicolumn{2}{|c|}{$734.8 \pm 234.4$} & $893.8 \pm 276.9$ & $948.1 \pm 378.0$ & $0.987^{a}$ & $0.034^{*}$ \\
\hline FRAP (mmol) & $4.03 \pm 1.96$ & \multicolumn{2}{|c|}{$3.10 \pm 1.13$} & $3.56 \pm 1.07$ & $4.01 \pm 1.71$ & 0.739 & $0.024^{*}$ \\
\hline Serum TAC (mmol/L) & \multicolumn{3}{|c|}{$1.586 \pm 0.26$} & \multicolumn{2}{|c|}{$1.684 \pm 0.26$} & \multicolumn{2}{|c|}{$0.103^{a}$} \\
\hline Serum TOS $(\mu \mathrm{mol} / \mathrm{L})$ & \multicolumn{3}{|c|}{$13.275 \pm 4.267$} & \multicolumn{2}{|c|}{$8.846 \pm 1.776$} & \multicolumn{2}{|c|}{$<0.001^{\star}$} \\
\hline OSI & \multicolumn{3}{|c|}{$0.876 \pm 0.359$} & \multicolumn{2}{|c|}{$0.541 \pm 0.143$} & \multicolumn{2}{|c|}{$<0.001^{\star}$} \\
\hline
\end{tabular}

Mann-Whitney $U$ test; $p_{1}$ value: tested between male older and younger adults; $p_{2}$ value: tested between female older and younger adults

aStudent's t test, ${ }^{*} \mathrm{p}<0.05$

TAC: total antioxidant capacity, ORAC: oxygen radical absorbance capacity, TE: Trolox equivalents, TP: total phenol, GAE: gallic acid equivalents, FRAP: ferric reducing antioxidant power, TOS: total oxidant status, OSI: oxidative stress index

Table 4. Correlation between dietary diversity score, serum total antioxidant capacity, and dietary total antioxidant capacity

\begin{tabular}{|c|c|c|c|c|}
\hline \multirow[b]{2}{*}{ Dietary TAC } & \multicolumn{2}{|c|}{ DDS } & \multicolumn{2}{|c|}{ Serum TAC } \\
\hline & $r$ & $\mathbf{P}$ & $r$ & $p$ \\
\hline H-ORAC ( $\mu \mathrm{mol}$ TE) & 0.237 & $0.039 *$ & 0.228 & $0.048^{*}$ \\
\hline L-ORAC ( $\mu \mathrm{mol}$ TE) & 0.398 & $<0.001$ * & 0.145 & 0.211 \\
\hline T-ORAC ( $\mu \mathrm{mol}$ TE) & 0.291 & $0.011^{*}$ & 0.237 & $0.039 *$ \\
\hline TP (GAE) & 0.256 & $0.029 a *$ & 0.196 & $0.090^{a}$ \\
\hline
\end{tabular}

Spearman's correlation. ${ }^{*} p<0.05$

aPearson's correlation

DDS: dietary diversity score, TAC: total antioxidant capacity, ORAC: oxygen radical absorbance capacity, TE: Trolox equivalents, TP: total phenol, GAE: gallic acid equivalents, FRAP: ferric reducing antioxidant power 
TOS and OSI were higher among the older adults. Furthermore, the dietary diversity was lower among the older adults than among the younger adults. Nutritional recommendations for healthy individuals and patients, particularly the elderly, should encourage the consumption of various foods belonging to all food groups.

\section{Acknowledgments}

The authors thank the patients who participated voluntarily in this study.

\section{REFERENCES}

1. Turkish Statistical Institute (TUIK). Population by Years, Age Group and Sex, Census of Population; 2019. [Internet]. Available from: https://data.tuik.gov. tr/Bulten/Index?p=Elderly-Statistics-2019-33712. Accessed: 20.01.2021

2. Rahman K. Studies on free radicals, antioxidants, and co-factors. Clin Interv Aging 2007; 2(2): 219-236. (PMID: 18044138)

3. Pérez VI, Bokov A, Remmen HV, et al. Is the oxidative stress theory of aging dead? Biochim Biophys Acta Gen Subj 2009; 1790(10): 1005-14. (PMID: 19524016)

4. Shahidi F, Ambigaipalan P. Phenolics and polyphenolics in foods, beverages and spices: Antioxidant activity and health effects - A review. J Funct Foods 2015; 18: 820-97. (DOI: 10.1016/j.jff.2015.06.018)

5. Nascimento-Souza MA, Paiva PG, Martino HSD, Ribeiro AQ. Dietary total antioxidant capacity as a tool in health outcomes in middle-aged and older adults: A systematic review. Crit Rev Food Sci Nutr 2018; 58(6): 905-12. (PMID: 27646047)

6. U.S. Department of Agriculture, Agricultural Research Service. Oxygen Radical Absorbance Capacity (ORAC) of Selected Foods, Release 2. Nutrient Data Laboratory; 2010. [Internet]. Available from: https://www.ars.usda.gov/research/publications/publication/?seqNo115=251105 Accessed: 02.09.2020

7. Carlsen $\mathrm{MH}$, Halvorsen $\mathrm{BL}$, Holte $\mathrm{K}$, et al. The total antioxidant content of more than 3100 foods, beverages, spices, herbs and supplements used worldwide. Nutr J 2010; 9(1): 3. (PMID: 20096093)

\section{Funding}

No financial support was received from any institution or organization for this work

\section{Competing interest}

The authors declare that they have no conflict of interest.

8. Turkey Dietary Guidelines, Ministry of Health of Turkey Publication No:1046, Ankara 2016. pp 177-90. (in Turkish)

9. Haines P, M Siega-Riz A, Popkin B. The Diet Quality Index revised: a measurement instrument for populations. J Am Diet Assoc 1999; 99(6): 697-704. (PMID: 10361532)

10. Erel O. A novel automated direct measurement method for total antioxidant capacity using a new generation, more stable ABTS radical cation. Clin Biochem 2004; 37(4): 277-85. (PMID: 15003729)

11. Erel O. A new automated colorimetric method for measuring total oxidant status. Clin Biochem 2005; 38(12): 1103-11. (PMID: 16214125)

12. Liguori I, Russo G, Curcio F, et al. Oxidative stress, aging, and diseases. Clin Interv Aging 2018; 13: 75772. (PMID: 29731617)

13. Sluijs I, Cadier E, Beulens JWJ, van der A DL, Spijkerman AMW, van der Schouw YT. Dietary intake of carotenoids and risk of type 2 diabetes. Nutr Metab Cardiovasc Dis 2015; 25(4): 376-81. (PMID: 25716098)

14. Banim PJR, Luben R, McTaggart A, et al. Dietary antioxidants and the aetiology of pancreatic cancer: a cohort study using data from food diaries and biomarkers. Gut 2013; 62(10): 1489-96. (PMID: 22826513)

15. Dietrich $M$, Block G, Norkus EP, et al. Smoking and exposure to environmental tobacco smoke decrease some plasma antioxidants and increase gamma-tocopherol in vivo after adjustment for dietary antioxidant intakes. Am J Clin Nutr 2003; 77(1): 160-6. (PMID: 12499336) 
16. Ignatowicz E, Wozniak A, Kulza M, et al. Exposure to alcohol and tobacco smoke causes oxidative stress in rats. Pharmacol Rep 2013; 65(4): 906-13. (PMID: 24145085)

17. Foote K, Bennett MR. Molecular insights into vascular aging. Aging (Albany NY) 2018; 10(12): 3647-9. (PMID: 30521484)

18. Smolin LA, Grosvenor MB, Gurfinkel D. Chapter 16. Nutrition and Aging: The Adult Years. Nutrition: Science and Applications. 2th Canadian edition, Wiley, United States 2015, pp 1-24.

19. Republic of Turkey Ministry of Health, Public Health Agency of Turkey. Turkey Nutrition and Health Survey (TNHS)-2010. [Internet]. Available from: https:// hsgm.saglik.gov.tr/depo/birimler/saglikli-beslenmehareketli-hayat-db/Yayinlar/kitaplar/diger-kitaplar/ TBSA-Beslenme-Yayini.pdf. Accessed: 02.09.2020 (in Turkish)

20. World Health Organisation. Diet, nutrition and the prevention of chronic diseases. World Health Organization technical report series 2003; 916: i-viii, 1-149. [Internet]. Available from: https://www.who.int/dietphysicalactivity/publications/trs916/en/. Accessed: 03.09.2020
21. Habte T-Y, Krawinkel M. Dietary Diversity Score: A measure of nutritional adequacy or an indicator of healthy diet? J Nutr Health Sci 2017; 3(3): 303. (DOI: 10.15744/2393-9060.3.303)

22. Otsuka R, Nishita Y, Tange C, et al. Age-related 12year changes in dietary diversity and food intakes among community-dwelling Japanese aged 40 to 79 years. J Nutr Health Aging 2018; 22(5): 594-600. (PMID: 29717759)

23. Zujko M, Witkowska A, Waskiewicz A, Mirończuk-Chodakowska I. Dietary Antioxidant and Flavonoid Intakes Are Reduced in the Elderly. Oxid Med Cell Longev 2015; 2015: 843173. (PMID: 26236427)

24. Narmaki E, Siassi F, Koohdani F, et al. Dietary diversity as a proxy measure of blood antioxidant status in women. Nutrition 2015; 31(5): 722-6. (PMID: 25837219)

25. Wang Y, Yang M, Lee SG, Davis CG, Koo SI, Chun OK. Dietary total antioxidant capacity is associated with diet and plasma antioxidant status in healthy young adults. J Acad Nutr Diet 2012; 112(10): 162635. (PMID: 23017573) 